\section{The Charlson comorbidity index (CCl) for adjustment of hip fracture mortality in the elderly: analysis of the importance of recording secondary diagnoses}

\author{
Aplicação do índice de comorbidade de Charlson \\ (ICC) no ajuste de risco da mortalidade após \\ fratura proximal de fêmur em idosos: análise \\ da importância dos diagnósticos secundários
}

Rômulo Cristovão de Souza 1

Rejane Sobrino Pinheiro 2

Cláudia Medina Coeli 2,3

Kenneth Rochel de Camargo Jr. 3

\footnotetext{
${ }^{1}$ Fundação Educacional Serra dos Órgãos,

Teresópolis, Brasil.

2 Faculdade de Medicina, Universidade Federal do Rio de Janeiro, Brasil. 3 Instituto de Medicina Social, Universidade do Estado do Rio de Janeiro, Rio de Janeiro, Brasil.

Correspondence R. C. Souza Coordenação do Curso de Enfermagem, Fundação Educacional Serra dos Órgãos.

Av. Alberto Torres 111, Teresópolis, $R J$ 25964-004, Brasil. romulocsouza@oi.com.br
}

\begin{abstract}
This study evaluates the role of the number of secondary diagnoses for calculating the Charlson comorbidity index (CCI) in risk adjustment of the 90-day mortality rate after hip fracture surgical repair. Comorbidities were selected by reviewing the medical records of 390 patients 50 years of age or older in a teaching hospital in Rio de Janeiro from 1995 to 2000. Logistic regression models were fitted including the variables age, sex, and CCI. The CCI was calculated based on: (1) all patients' comorbidities; (2) only the comorbidity with the highest weight; and (3) a single randomly selected comorbidity. There was a gradient in the prediction of the CCI mortality rate when all comorbidities were used $(O R=6.53$; 95\%CI: 2.27-18.77, for scores $\geq 3$ ). The predictive capacity of the CCI was observed even when it was calculated using only one comorbidity: with the highest weight (OR=2.83; 95\%CI: 1.11-7.22); and randomly selected $(\mathrm{OR}=2.90$; 95\%CI: 1.077.81). Using all comorbidities for CCI calculation is important. Severity indices based on a single comorbidity can be useful for risk adjustment procedures.
\end{abstract}

Femoral Fractures; Comorbidity; Mortality

\section{Introduction}

Outcomes analysis has been used to evaluate the care provided to health services users and can be conducted through performance measurements. These measurements include the mortality rate as a traditional indicator, already reported by Codman in the early $20^{\text {th }}$ century as having the capacity to express a crucial dimension of care, namely the outcome 1,2,3.

According to Travassos et al. 1, data on inhospital or post-discharge patient mortality can fulfill two goals: (1) determine a hospital's performance over time and (2) monitor the performance of a group of hospitals over a period of time. Differences in care can be explained by factors related to the profile of patients treated, which requires the application of mechanisms that allow performing risk adjustment, aimed at controlling the effects of variables that alter the outcome, independently of quality of care. Adjustment considers patient characteristics like age, gender, socioeconomic status, severity of primary diagnosis, functional, psychological, cognitive, and psychosocial status, and extent and severity of coexisting diseases or comorbidities $4,5,6,7$.

Administrative databases have been used increasingly to evaluate hospital care outcomes 6,8 . Such databases display advantages like low cost of data retrieval, large amounts of patient records, and possibility of using data in differ- 
ent types of research. Meanwhile, the scarcity of clinical data and low reliability of information are identified as the principal disadvantages 1 . Although administrative databases are not originally designed for evaluation studies, they can serve as an important tool to provide responses for the health sector.

Few people would disagree as to the need to consider case severity in risk adjustment, even though there is no definition as to the best way to measure it 9 . Comorbidities, or all the diseases listed as secondary diagnoses and that can be measured by number and severity, are important predictive factors for adverse outcomes and play a key role in adjustment 8,10,11,12.

The Charlson comorbidity index (CCI) is a system for classification of severity that uses recorded data on secondary diagnoses to assign a weight to morbidity, thereby generating the patient's risk of death. The method was developed from a cohort of 604 hospital patients in the United States to predict one-year mortality and was validated in a cohort of 685 women with breast cancer followed for 10 years 13,14. The final CCI score is the sum of the weights assigned to 19 predetermined clinical conditions 13 , listed in Table 1. This score can be combined with age to form a single index. Thus, one point for each additional 10 years is added to the initial score 13 .

The method proposed by Charlson was adapted to obtain data on comorbidities, coded according to the International Classification of Diseases, 9th Revision, Clinical Modification (ICD-9 $\mathrm{CM})$, based on computerized data contained in hospital discharge summaries 4,8,11,15,16,17,18. Although differences can be found in the weights of patients' comorbidities as a function of the coding adopted by these adaptations, studies have shown that there is no significant change in the CCI's capacity to predict mortality, as compared to the results of these adaptations 4,8,17.

In Brazil, the application of measures to adjust health outcomes risk is rare, and the use of administrative databases is recent. The Hospital Information System of the Unified National Health System (SIH/SUS), otherwise known as the Hospital Admissions Authorization System (AIH), includes information on the care provided in the entire national network financed by the public sector. The SIH/SUS has been the main source of data for evaluation studies, even with the limitations intrinsic to an administrative database, including the small number of fields for recording diagnoses 6,7,19.

Martins et al. 6 used the CCI for risk adjustment in 40,299 hospital admissions in the Municipality of Rio de Janeiro, based on the SIH/ SUS. The authors concluded that although it was important for predicting mortality, a comorbidity hardly discriminated the severity of cases, and that age was the most important predictor of mortality risk, next to the primary diagnosis. Two factors were presented to explain this result: limited space for recording secondary diagnoses - the SIH/SUS has only one field for secondary diagnosis; and under-recording of the secondary diagnosis - only $18.6 \%$ of the 40,299 admissions had it recorded. These authors suggest that CCI be associated with age (combined CCI) for purposes of risk adjustment in the mortality rate, calculated on the basis of SIH/SUS data.

In the case of elderly patients, whose health is generally more frail, knowledge of a comorbidity can help explain unfavorable health outcomes, suggesting that the use of at least one secondary diagnosis can help predict mortality. Although the secondary diagnosis is rarely filled out in the $\mathrm{SIH} / \mathrm{SUS}$ form, in the case of hip fractures in Rio de Janeiro the rate is considered high, over $90 \%$ (DATASUS; http://www.datasus.gov.br, accessed on $01 /$ Aug/2005). However, this secondary diagnosis usually refers to external causes like fall from height or accidents.

The present study aimed to assess the use of CCI as a 90-day mortality risk adjustment method in elderly patients hospitalized for hip fracture repair, using all the information on comorbidities recorded in the patient medical chart and one comorbidity only. The purpose was to compare the use of the index in the ideal situation, using the patient medical chart as the data source, with simulation of what would occur if a hospital administrative database had been used containing only one secondary diagnosis.

\section{Material and methods}

The data used in this study pertained to a survey of elderly patients hospitalized for surgical hip fracture repair at a university hospital in the municipality of Rio de Janeiro, Brazil, from 1995 to 2000. Patient charts were searched for coexisting diseases, recorded with the first three digits of ICD-9. The probabilistic record linkage method was applied, as proposed by Coeli \& Camargo 20, comparing the hospital database and the Mortality Information System (SIM), for the years 1995 to 2001 , aimed at identifying possible deaths within 90 days after the hospitalization date.

The CCI was calculated on the basis of all the comorbidities recorded for the patient (complete Charlson) and also based on a single comorbidity, selected among those used initially. This selection process was done in two ways: (1) using only one of the coexisting diseases, that with the 
Weights of clinical conditions referring to secondary diagnosis, considered in the Charlson comorbidity index.

\begin{tabular}{ll}
\hline Weights & \multicolumn{1}{c}{ Clinical conditions } \\
\hline 1 & $\begin{array}{l}\text { Myocardial infarct; congestive heart failure; peripheral vascular disease; dementia; } \\
\text { cerebrovascular disease; chronic lung disease; connective tissue disease; ulcer; chronic liver disease } \\
\text { Hemiplegia; moderate or severe kidney disease; diabetes; diabetes with complication; tumor; } \\
2\end{array}$ \\
& $\begin{array}{l}\text { leukemia; lymphoma } \\
6\end{array}$ \\
\hline
\end{tabular}

highest weight among the pre-established clinical conditions (highest Charlson), based on the table with the construction of the Charlson Comorbidity Index (Table 1) or (2) using only one disease, defined by random selection (random Charlson). This selection used a Clipper compiler function, which generated a random number from 1 to $n$, where $n$ was equal to the patient's number of comorbidities. Calculating the CCI using one comorbidity only aimed to create, in the database used by the current study, a similar situation to that of the SIH/SUS form, which has only one field for recording secondary diagnosis. Age was not combined with the CCI.

Logistic regression was used to measure the effect of CCI on predicting 90-day mortality after hip fracture. The variables related to CCI were grouped in $0,1,2$, and 3 or more. Age was treated as continuous. The initial model (Table 1) used the variables sex and age. A model was constructed for each of the proposed risk adjustments, controlled by sex and age.

\section{Results}

Of the 390 selected patients (Table 2), 276 (70.8\%) were females and $114(29.2 \%)$ were males. Mean age was 74.8 years $(S D=10.7)$. Some $70 \%$ of the patients had up to two comorbidities and only $4.6 \%$ had five or more coexisting diseases. The mean number of comorbidities was 1.9. For the CCI calculated with all the comorbidities (complete Charlson), $57.9 \%$ of patients received a score of $0,16.4 \%$ a score of $1,18.2 \%$ a score of 2 , and $7.5 \%$ a score of 3 or more. None of the clinical conditions presented by patients scored greater than 2, based on the list proposed by Charlson (Table 1), and thus the CCIs calculated on the basis of a single comorbidity did not score greater than 2. For the CCI calculated using the diagnosis with the highest weight (highest Charlson), 57.7\% of the patients were classified with a score of 0 , $20.5 \%$ with 1 , and the other $21.8 \%$ with 2 . Using a randomly selected diagnosis (random Charlson), $77.9 \%$ of the cases received a score of $0,11.8 \%$ score 1 , and only $10.3 \%$ score 2 .

The 90 -day mortality rate was $7.4 \%$. Gender was not associated with 90-day mortality in any of the models, unlike age (Table 3), which was associated with risk of dying both in the adjustment by sex and age alone (initial model) and in the different models including CCI (highest, random, and complete Charlson models). In the models in which the CCI was calculated on the basis of only one comorbidity (highest and random Charlson), the 90-day mortality rate was higher for a CCI of 1 as compared to 0 , but no statistically significant association was observed with death for a score of 2 as compared to 0 . The odds ratios were similar for these two models, and the 90-day odds of death for CCI equal to 1 was approximately 2.9 that for a score of 0 . An association was observed between CCI and 90-day mortality when the index was calculated according to all comorbidities. The complete Charlson model showed a gradient in the 90-day mortality odds in relation to patients with a CCI of 0 , beginning at score 2 , although without statistical significance, and odds of dying 6.5 times greater among patients who scored 3 or more.

\section{Discussion}

Risk adjustment has been identified as a necessary strategy for evaluating health care outcomes, and knowledge of the severity of patients' comorbidities is part of this adjustment 8,9,11,17. Coexisting diseases are measured both in number and severity to determine severity. There are various models for measuring comorbidities, including the CCI ${ }^{15}$. Since these methods are based on secondary diagnoses, the number of fields for re- 
Profile of patients admitted to a university hospital in the municipality of Rio de Janeiro, Brazil, for proximal hip fracture from 1995 to 2000.

\begin{tabular}{|c|c|c|}
\hline Variable & $\mathrm{n}$ & $\%$ \\
\hline \multicolumn{3}{|l|}{ Sex } \\
\hline Male & 114 & 29.2 \\
\hline Female & 276 & 70.8 \\
\hline \multicolumn{3}{|l|}{ Age (years) } \\
\hline $50-59$ & 38 & 9.8 \\
\hline $60-69$ & 82 & 21.0 \\
\hline $70-79$ & 116 & 29.7 \\
\hline $80-89$ & 131 & 33.6 \\
\hline $90-99$ & 23 & 5.9 \\
\hline \multicolumn{3}{|c|}{ Mean $=74.8(S D=10.7)$} \\
\hline \multicolumn{3}{|c|}{ Number of comorbidities } \\
\hline 0 & 67 & 17.2 \\
\hline 1 & 103 & 26.4 \\
\hline 2 & 105 & 26.9 \\
\hline 3 & 57 & 14.6 \\
\hline 4 & 40 & 10.3 \\
\hline 5 & 11 & 2.8 \\
\hline 6 & 2 & 0.5 \\
\hline 7 & 3 & 0.8 \\
\hline 9 & 2 & 0.5 \\
\hline \multicolumn{3}{|c|}{ Mean $=1.9(\mathrm{SD}=1.5)$} \\
\hline \multicolumn{3}{|c|}{ Highest CCl } \\
\hline 0 & 225 & 57.7 \\
\hline 1 & 80 & 20.5 \\
\hline 2 & 85 & 21.8 \\
\hline \multicolumn{3}{|c|}{$\mathrm{CCl}$ (random Charlson) } \\
\hline 0 & 304 & 77.9 \\
\hline 1 & 46 & 11.8 \\
\hline 2 & 40 & 10.3 \\
\hline \multicolumn{3}{|c|}{$\mathrm{CCl}$ (complete Charlson) } \\
\hline 0 & 226 & 57.9 \\
\hline 1 & 64 & 16.4 \\
\hline 2 & 71 & 18.2 \\
\hline$\geq 3$ & 29 & 7.5 \\
\hline \multicolumn{3}{|c|}{ 90-day mortality } \\
\hline Yes & 29 & 7.4 \\
\hline No & 361 & 92.6 \\
\hline Total & 390 & 100.0 \\
\hline
\end{tabular}

$\mathrm{CCl}$ : Charlson comorbidity index.

cording them and the quality of the information are important for the final classification.

Based on the results, the CCI calculated with all the comorbidities recorded for the patient was associated with 90-day mortality according to a gradient, although statistical significance was only observed for the highest score (3 or more). Even when only one secondary diagnosis was available, the effect of this index on the target outcome was observed, but without a gradient, as occurred with the complete CCI. It was interesting that the index had an effect on 90day mortality for a score of 1 and that it was not significant for score 2 , as compared to score 0 . A possible explanation is the fact that the CCI is not a specific index for classifying mortality risk 
Logistic regression models for risk adjustment of 90-mortality following hip facture according to the Charlson comorbidity index $(\mathrm{CCl})$.

\begin{tabular}{|c|c|c|c|}
\hline Model/Variable & Coefficient & OR & $95 \% \mathrm{Cl}$ \\
\hline \multicolumn{4}{|l|}{ Initial * } \\
\hline \multicolumn{4}{|l|}{ Sex } \\
\hline Female & 0.00 & 1.00 & \\
\hline Male & 0.28 & 1.25 & $0.52-3.01$ \\
\hline Age & 0.06 & 1.06 & $1.01-1.10$ \\
\hline \multicolumn{4}{|l|}{ Highest $\mathrm{CCl}$ ** } \\
\hline \multicolumn{4}{|l|}{ Sex } \\
\hline Female & 0.00 & 1.00 & \\
\hline Male & 0.08 & 1.08 & $0.44-2.69$ \\
\hline Age & 0.06 & 1.06 & $1.02-1.10$ \\
\hline \multicolumn{4}{|l|}{$\mathrm{CCl}$} \\
\hline 0 & 0.00 & 1.00 & \\
\hline 1 & 1.04 & 2.83 & $1.11-7.22$ \\
\hline 2 & 0.65 & 1.92 & $0.72-5.10$ \\
\hline \multicolumn{4}{|l|}{ Random $\mathrm{CCl}^{\star \star \star \star}$} \\
\hline \multicolumn{4}{|l|}{ Sex } \\
\hline Female & 0.00 & 1.00 & \\
\hline Male & 0.08 & 1.08 & $0.43-2.71$ \\
\hline Age & 0.06 & 1.06 & $1.02-1.11$ \\
\hline \multicolumn{4}{|l|}{$\mathrm{CCl}$} \\
\hline 0 & 0.00 & 1.00 & \\
\hline 1 & 1.06 & 2.90 & $1.07-7.81$ \\
\hline 2 & 0.68 & 1.98 & $0.61-6.42$ \\
\hline \multicolumn{4}{|l|}{ Complete $\mathrm{CCl} \#$} \\
\hline \multicolumn{4}{|l|}{ Sex } \\
\hline Female & 0.00 & 1.00 & \\
\hline Male & 0.07 & 1.07 & $0.42-2.72$ \\
\hline Age & 0.06 & 1.06 & $1.01-1.11$ \\
\hline \multicolumn{4}{|l|}{$\mathrm{CCl}$} \\
\hline 0 & 0.00 & 1.00 & \\
\hline 1 & -0.18 & 0.83 & $0.22-3.18$ \\
\hline 2 & 0.49 & 1.64 & $0.57-4.68$ \\
\hline$\geq 3$ & 1.88 & 6.53 & $2.27-18.77$ \\
\hline
\end{tabular}

* Considering only the individual's variables in the SIH-SUS;

** $\mathrm{CCl}$ for one secondary diagnosis, comorbidity with the highest weight according to Charlson;

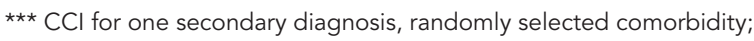

\# $\mathrm{CCl}$ calculated for all the comorbidities.

in hip fracture patients, but a general index that captures the patient's severity trend as it incorporates various comorbidities. In the models that incorporated only one comorbidity for calculating CCI, score 1 especially represented comorbidities related to the respiratory and cardiovascular systems and dementia, probably more associated with 90-day mortality in hip fracture patients than the comorbidities with weights greater than 1, although quite severe in general.
The results point to the importance of patients' comorbidity profile for mortality odds, and that recording this information should be prioritized by information systems.

The inclusion of fields for recording comorbidities is an issue that adds to the discussion on quality of data collection. The SIH/SUS form has only one field for secondary diagnosis, generally poorly filled and considered a limitation in analyses of hospital care outcomes. 
The low capacity to discriminate the severity of cases using CCI in the SIH/SUS databases was demonstrated by Martins et al. ${ }^{6}$. According to these authors, this fact was due primarily to the limited space for recording diagnoses - one field for the principal diagnosis and one for the secondary diagnosis. The findings presented here suggest that the addition of fields for diagnostic discrimination in administrative databases may increase the mortality prediction by the CCI. The limitation posed by the SIH/SUS form in terms of reduced space for recording secondary diagnoses has an effect on the risk adjustment methods that consider these diagnoses for assessing the patient's severity. This effect can be observed specifically for the CCI, since the final score is produced cumulatively based on the weight of each clinical condition identified in that patient and is thus sensitive to the recording of diagnostic information.

However, the CCI showed an effect even when based on only one field for recording secondary diagnoses. In a situation where only one field is available for recording secondary diagnoses, the use of specific indices for the target health problem is extremely important for allowing better classification of patients as to mortality risk.

Since calculation of the CCI uses weights assigned to clinical conditions selected from a list that is predefined by the method, some diseases not included in this list may also explain the mortality of patients with specific health problems. Thus, some authors propose that the incorporation of other diseases could increase the predictive capability 4,17 . Martins 21 developed a new index based on the CCI and the inclusion of other originally excluded clinical conditions and contends that there was an improvement in the method's discrimination. Still, the author highlights that the new index was created with data from only one region and that it would be necessary to validate it in other populations before generalizing it nationwide.

However, the discussion on improving the quality of data available for risk adjustment should not be limited to recording comorbidities. It also includes the issue of data recording, since low completion of fields is a serious problem. Escosteguy et al. 19, in an article on the Hospital Information System and care for acute myocardial infarct, commenting on the precision of variables in the SIH/SUS form, state that the system's greatest limitation is the precarious nature of secondary diagnoses, not only because only one diagnosis can be recorded, but also because this field is rarely filled. According to Martins \& Travassos 22, the addition of spaces in the databases for keying in diagnostic codes is not sufficient in itself to improve the information. Measures are also needed to guarantee adequate recording of these codes in the primary data sources, which include information on the patient and the procedures performed while during care. According to Librero et al. 23 , the small number of fields available for recording diagnostic information may be a cause of under-recording diagnoses.

Finally, if the use of risk adjustment methods for studying mortality aims to assess the quality of care, another question should be raised. Since these methods use data from hospital discharge summaries, which include all the problems treated during hospitalization, it becomes important to distinguish whether these problems were present at the time of admission or emerged subsequently as complications. The confounding between comorbidity and complication can affect the result of risk adjustment methods like the CCI 9,17 .

Thus, some suggestions have been made: (1) more fields for recording secondary diagnoses; (2) information on the date of each diagnosis recorded; (3) standardization of discharge summaries; (4) discharge summary improvement and supervision; (5) human resources investment for training personnel in identifying and coding diagnoses; (6) physician education on the importance of coding; (7) use of the data and wide dissemination of the results $6,16,22$

One of this study's limitations is the possible occurrence of errors in the identification of deaths. However, it is important to emphasize that a careful review was performed of the hospital admission records and related deaths, applying rigorous criteria to finally classify a relationship as true. In studies using the probabilistic record linkage method, it is recommended to choose classification rules that minimize the occurrence of false positives, since these have a greater impact on the validity of ratio type measures than false negative errors. False negative results of the linkage process, when the sensitivity is nondifferential in relation to the exposure variable levels (non-informative errors), tend to bias the measures of difference towards the null, but not ratio type measures 24 . Studies on the accuracy of the probabilistic record linkage method are rare, due to the limited availability of information on target outcomes that can be considered a gold standard. A study in Brazil by Coutinho \& Coeli 25 , which investigated a probabilistic relationship between a primary database (a cohort of hospitalized elderly hip fracture patients) and the Mortality Information System, found sensitivity of $85.5 \%$ and specificity of $99.4 \%$ for the method. This study used databases and a methodology similar to the one in the present study. Thus, one 
can expect accuracy values close to those found by Coutinho \& Coeli 25, especially for specificity, since a careful review of the relationships was performed.

Concluding, although the addition of fields is important for risk adjustment in mortality analyses, even the consideration of only one diagnosis can be useful in the classification of patient severity, especially if weights are considered that are specially constructed for the target health problem.

\section{Resumo}

Este estudo visa a analisar o papel do número de diagnósticos secundários no cálculo do índice de comorbidade de Charlson (ICC) no ajuste de risco da mortalidade 90 dias após cirurgia reparadora de fratura proximal de fêmur. Obtiveram-se as comorbidades por revisão dos prontuários de 390 pacientes com 50 anos ou mais de um hospital universitário no Município do Rio de Janeiro, Brasil, 1995 a 2000. Ajustaram-se modelos de regressão logística incluindo as variáveis idade, sexo e ICC. Calculou-se o ICC com: (1) todas as comorbidades do paciente; (2) apenas a comorbidade com maior peso; (3) apenas uma comorbidade sorteada. Houve gradiente na chance de óbito em função do ICC usando-se todas as comorbidades $(R C=6,53$; IC95\%: 2,27-18,77, escore 3 ou mais). Observou-se a capacidade de predição do ICC calculado com apenas uma comorbidade, entretanto apenas para o escore 1 em comparação ao 0 : com maior peso $(R C=2,83$; IC95\%: 1,11-7,22); sorteada $(R C=2,90$; IC95\%: 1,077,81). É importante utilizar todas as comorbidades no ajuste de risco da mortalidade. Usar apenas um diagnóstico pode ser útil na classificação da gravidade do paciente.

Fraturas do Fêmur; Comorbidade; Mortalidade

\section{Contributors}

R. C. Souza conducted the record linkage analysis and participated together with the other authors in the data analysis and discussion of the results. 


\section{References}

1. Travassos C, Noronha, JC, Martins M. Mortalidade hospitalar como indicador de qualidade: uma revisão. Ciênc Saúde Coletiva 1999; 4:367-81.

2. Normand ST, Glickman ME, Sharma RGVRK, McNeill B. Using admission characteristics to predict short-term mortality from myocardial infarction in elderly patients: results from the Cooperative Cardiovascular Project. JAMA 1996; 275:1322-8.

3. Iucif Jr. N, Rocha JSY. Estudo da desigualdade na mortalidade hospitalar pelo índice de comorbidade de Charlson. Rev Saúde Pública 2004; 38:780-6.

4. Ghaly WA, Hall RE, Amy KR, Ash AS, Moskowitz MA. Searching for an improved clinical comorbidity index for use with ICD-9-CM administrative data. J Clin Epidemiol 1996; 49:273-8.

5. Iezzoni LI. The risks of risk adjustment. JAMA 1997; 278:1600-7.

6. Martins MS, Travassos C, Noronha JC. Sistema de informações hospitalares como ajuste de risco em índices de desempenho. Rev Saúde Pública 2001; 35:185-92.

7. Noronha JC, Martins M, Travassos C, Campos MR, Maia P, Panezzuti R. Aplicação da mortalidade hospitalar após a realização de cirurgia de revascularização do miocárdio para monitoramento do cuidado hospitalar. Cad Saúde Pública 2004; 20 Suppl 2:S322-30.

8. Cleves MA, Sanchez N, Draheim M. Evaluation of two competing methods for calculating Charlson's comorbidity index when analyzing short-term mortality using administrative data. J Clin Epidemiol 1997; 50:903-8.

9. Iezzoni LI, Shwartz M, Ash A, Hughes J, Daley J, Mackiernan YDBA. Severity measurement methods and judging hospital death rates for pneumonia. Med Care 1996; 34:11-28.

10. Brailer DJ, Kroch E, Pauly MV, Huang J. Comorbidity-adjustment complication risk: a new outcome quality measure. Med Care 1996; 34:490-505.

11. van Doorn C, Borgardus ST, Williams CS, Concato J, Towle VR, Inouye SK. Risk adjustment for older hospitalized persons: a comparison of two methods of data collection for the Charlson index. J Clin Epidemiol 2001; 54:694-701.

12. Groll DL, To T, Bombardier C, Wright JG. The development of a comorbidity index with physical function as the outcome. J Clin Epidemiol 2005; 59:595-602.

13. Charlson ME, Pompei P, Ales KL, MacKenzie R. A new method of classifying prognostic comorbidity in longitudinal studies: development and validation. J Chronic Dis 1987; 40:373-83.
14. Charlson ME, Szatrowski TP, Peterson J, Jeffrey G. Validation of a combined comorbidity index. J Clin Epidemiol 1996; 47:1245-51.

15. Needham, DM, Scales, DC, Laupacis A, Pronovost PJ. A systematic review of the Charlson comorbidity index using Canadian administrative databases: a perspective on risk adjustment in critical care research. J Crit Care 2005; 20:12-9.

16. Groot V, Beckerman H, Lankhorst GJ, Bouter LM. How to measure comorbidity: a critical review of available methods. J Clin Epidemiol 2003; 56:221-9.

17. D'Hoore W, Bouckeart A, Tilquin C. Practical considerations on the use of the Charlson comorbidity index with administrative data bases. J Clin Epidemiol 1996; 49:1429-33.

18. Romano OS, Chan BK, Schembri ME, Rainwater JA. Can administrative data bases be used to compare postoperative complication rates across hospitals? Med Care 2002; 40:856-67.

19. Escosteguy CC, Portela MC, Medronho RA, Vasconcellos MTM. O sistema de informações hospitalares e a assistência ao infarto agudo do miocárdio. Rev Saúde Pública 2002; 36:491-9.

20. Coeli CM, Camargo Jr. K. Avaliação de diferentes estratégias de blocagem no relacionamento probabilístico de registros. Rev Bras Epidemiol 2002; 5:185-96.

21. Martins M. Durée de séjour et mortalité hospitalière au Brésil: comparaison entre hôpitaux publics et privés [Doctoral Dissertation]. Montreal: Université de Montréal; 2002.

22. Martins MS, Travassos C. Assessing the availability of casemix information in hospital database systems in Rio de Janeiro, Brazil. Int J Qual Health Care 1998; 10:125-33.

23. Librero J, Peiró S, Ordiñana R. Chronic comorbidity and outcomes of hospital care: length of stay, mortality, and readmission at 30 and 365 days. J Clin Epidemiol 1999; 52:171-9.

24. Howe G. Use of computerized record linkage in cohort studies. Epidemiol Rev 1998; 20:112-21.

25. Coutinho ESF, Coeli CM. Acurácia da metodologia de relacionamento probabilístico de registros para identificação de óbitos em estudos de sobrevida. Cad Saúde Pública 2006; 22:2249-52.

Submitted on 11/Apr/2006

Final version resubmitted on 15/May/2007

Approved on 23/May/2007 